\title{
Investigating the prevalence of Salmonella in dogs within the Midlands region of the United Kingdom
}

\author{
Preena Lowden ${ }^{1}$, Corrin Wallis ${ }^{2 *}$ Nancy Gee ${ }^{2}$ and Anthony Hilton ${ }^{1}$
}

\begin{abstract}
Background: The intimate relationship between dogs and their owners has the potential to increase the risk of human exposure to bacterial pathogens. Over the past 40 years, there have been several reports on transmission of salmonellae from dogs to humans. This study therefore aimed to determine the prevalence of Salmonella in the faeces of dogs from the Midlands region of the United Kingdom to assess exposure risk and potential for zoonotic transmission.

Results: A total of 436 apparently healthy dogs without diarrhoea from households ( $n=126)$, rescue centres $(n=96)$, boarding kennels $(n=43)$, retired greyhound kennels $(n=39)$ and a pet nutrition facility $(n=132)$ were investigated for Salmonella shedding. Faecal samples were processed by an enrichment culture based method. The faeces from one $\operatorname{dog}(0.23 \%$; $95 \%$ confidence limit $0.006 \%, 1.27 \%)$ was positive for Salmonella. The species was S. enterica subspecies arizonae.

Conclusion: This study showed that the prevalence of Salmonella from faeces from apparently healthy dogs from a variety of housing conditions is low; however, Salmonella shedding was still identified.
\end{abstract}

Keywords: Salmonella, Zoonosis, Dog, Epidemiology, Prevalence

\section{Background}

Salmonella is the aetiological agent of both human and animal salmonellosis, a very common and widely spread enteric disease. Over 7,500 human cases of Salmonella infections were reported in the United Kingdom (UK) in 2013 [1]. It has been estimated that $55 \%$ to $95 \%$ of human salmonellosis cases are foodborne and that approximately $9 \%$ are attributable to direct animal contact [2-5]. With respect to salmonellosis cases that may be attributable to pets the estimates are lower at approximately $3 \%$ [6]. According to the reports of physicians and veterinarians, salmonellosis rates as the second most serious zoonotic disease after toxoplasmosis. It poses most risk to children, the elderly and immunocompromised humans $[7,8]$.

In 2014, it was estimated that there were approximately nine million dogs in the UK [9]. Dog ownership

\footnotetext{
* Correspondence: corrin.wallis@effem.com

${ }^{2}$ WALTHAM Centre for Pet Nutrition, Waltham-on-the-Wolds, Leicestershire LE14 4RB, UK

Full list of author information is available at the end of the article
}

is associated with many benefits for people including companionship and physiological and psychological health [10-16]. In order to maximize these benefits it is also helpful to understand any risks to public health from zoonosis [17]. Over the past 40 years there have been several reports on transmission of salmonellae from dogs to humans $[18,19]$. Today, dogs in Western Europe primarily live indoors, share living spaces with their owners, and assume integral roles as companions, family members, or service animals [20, 21], and this more intimate relationship between dogs and their owners has the potential to increase the risk of human exposure to Salmonella.

Dogs have been reported to harbour and shed Salmonella subclinically. High numbers of the microorganism can reside in the intestines and mesenteric lymph nodes without clinical signs [22] making an estimate of the prevalence of salmonellae in dogs in the community difficult to establish. The prevalence of subclinical carriage of Salmonella in clinically healthy dogs varies greatly among individual countries and has been reported to 
range from 0 to $44 \%[23,24]$. However, recent studies on the prevalence of Salmonella in different populations of dogs within the UK are lacking [25-27]. The objective of this study was therefore to estimate, and potentially compare, subclinical carriage of Salmonella in dogs housed in a variety of settings, including household, pet nutrition facility and kennelled dogs from the Midlands region of the UK, to determine their potential as a source of Salmonella infection to humans.

\section{Results}

A total of 436 faecal samples were collected from different populations of dogs (see Table 1). Descriptive information on the sample of dogs in the study, breed groups (according to The Kennel Club Organisation [28]), age, sex, weight and diet, are provided in Table 2 . The majority of the dogs were from the gundog group with hound, pastoral and utility being the next most represented. This representation of breeds is similar to that reported by The Kennel Club Organisation as among the most popular in the UK based on current registrations [28]. The dogs ranged in age from 0.3 to 16 years and weights ranged from 2 to $48 \mathrm{~kg}$. There were 227 male and 209 female dogs in the study and the majority of females were intact $(64 \%)$ and the majority of males were neutered $(74 \%)$. A total of 30 dogs $(6.9 \%)$ were fed a home prepared diet and the remaining dogs $(93.1 \%)$ were fed a commercial diet. Only two dogs, representatives of the hound and gun dog breed groups, were fed a homeprepared raw meat diet.

Using an enrichment culture method along with three selective agars, only one of the 436 faecal samples $(0.23 \%, 95 \%$ confidence interval $0.006,1.27)$ was positive for Salmonella (see Table 1). The species was $S$. enterica subspecies arizonae. The Salmonella positive dog was a female terrier breed from a household population, aged four and weighing $7 \mathrm{~kg}$. The questionnaire
Table 1 Number of faecal samples analysed and the number positive for Salmonella from different dog populations

\begin{tabular}{llll}
\hline Population & $\begin{array}{l}\text { Total number } \\
\text { of dogs }\end{array}$ & $\begin{array}{l}\text { Number of dogs } \\
\text { Salmonella positive }\end{array}$ & $\begin{array}{l}\text { Salmonella } \\
\text { serotype }\end{array}$ \\
\hline Households & 126 & 1 & S. arizonae \\
Rescue centres & 96 & 0 & - \\
Boarding kennels & 43 & 0 & - \\
Retired greyhounds & 39 & 0 & - \\
Pet nutrition facility & 132 & 0 & - \\
\hline
\end{tabular}

revealed that the dog was fed a commercial diet (mix of wet and dry) and had a tendency to scavenge when outdoors in the garden. Subsequent repeat samples taken from this dog over three consecutive days, one week after the first sample, were negative for the presence of Salmonella.

When using direct culturing methods, none of the faecal samples in the study were positive for Salmonella shedding. When both direct and enrichment culturing methods were used, samples taken from kennel groups of dogs (rescue centres, boarding kennels, retired greyhounds and pet nutrition facility) were all negative for Salmonella shedding. Given the low prevalence of Salmonella, restricted to only one of the dog populations, further statistical comparisons between the household, pet nutrition facility and kennelled dogs was not undertaken as it was considered to be inconsequential.

\section{Discussion}

Apparently healthy dogs can harbour Salmonella and might thereby serve as a potential source of human infection with implications for public health. Almost a quarter of all UK households are home to at least one dog [9] and it is therefore important that we understand the risk of transmission of zoonotic infections. This study showed that the prevalence of Salmonella in dogs

Table 2 Breed group, age, gender, weight, and diets of dogs included in the study

\begin{tabular}{|c|c|c|c|c|c|c|c|c|c|c|c|c|c|c|c|}
\hline \multirow[t]{3}{*}{ Breed group } & \multirow{3}{*}{$\begin{array}{l}\text { Number } \\
\text { of dogs }\end{array}$} & \multirow{2}{*}{\multicolumn{2}{|c|}{ Age (years) }} & \multirow{2}{*}{\multicolumn{4}{|c|}{ Gender (no. of dogs) }} & \multirow{2}{*}{\multicolumn{2}{|c|}{ Weight (Kg) }} & \multicolumn{6}{|l|}{ Diet } \\
\hline & & & & & & & & & & \multicolumn{3}{|c|}{ Commercial } & \multicolumn{2}{|c|}{ Home prepared } & \multirow[t]{2}{*}{$\mathrm{C} \& \mathrm{H}$} \\
\hline & & Range & Median & $\mathrm{F}$ & $\mathrm{Fn}$ & $M$ & $\mathrm{Mn}$ & Range & Median & Wet & Dry & Mixed & Cooked & Raw & \\
\hline Gundog & 155 & $0.5-14$ & 5 & 48 & 27 & 21 & 59 & $6-39$ & 25 & 18 & 66 & 60 & 9 & 1 & 1 \\
\hline Hound & 68 & $2-15$ & 4 & 13 & 16 & 13 & 26 & $4-32$ & 22 & 1 & 44 & 22 & - & 1 & - \\
\hline Pastoral & 68 & $1-16$ & 6 & 23 & 8 & 4 & 33 & $13-38$ & 16 & 7 & 16 & 36 & 9 & - & - \\
\hline Terrier & 39 & $0.4-12$ & 3 & 18 & 0 & 7 & 14 & $3-28.5$ & 15.5 & 2 & 13 & 24 & - & - & - \\
\hline Toy & 9 & $1-6$ & 3 & 4 & 0 & 4 & 1 & $2-7$ & 4 & - & - & 8 & 1 & - & - \\
\hline Utility & 64 & $0.3-13.6$ & 3 & 16 & 15 & 6 & 27 & $8-36.3$ & 12 & 12 & 29 & 23 & & & \\
\hline Working & 14 & $3-8.1$ & 5 & 5 & 2 & 2 & 5 & $32-48$ & 32 & & 1 & 8 & 3 & - & 2 \\
\hline Cross Breeds & 19 & $1.6-14$ & 6 & 7 & 7 & 2 & 3 & $13-39.1$ & 22 & 1 & 2 & 13 & - & - & 3 \\
\hline Total & 436 & $0.3-16$ & 4.5 & 134 & 75 & 59 & 168 & $2-48$ & 19 & 41 & 171 & 194 & 22 & 2 & 6 \\
\hline
\end{tabular}

$F$ female, $M$ male, $F n$ female neutered, $M n$ male neutered, $C \& H$ commercial and home prepared 
located in the Midlands region of the UK is low $(0.23 \%$; $95 \%$ confidence interval $0.006 \%, 1.27$ ).

Other studies have estimated the prevalence of subclinical carriage of Salmonella in clinically healthy dogs to range from 0 to $44 \%[23,24]$. The results of the current study are in line with the lower estimates, but are inconsistent with the larger estimates. The prevalence of subclinical shedding of Salmonella in normal apparently healthy household dogs has been reported for a number of different countries. A study of 150 dogs from Hawke's Bay, New Zealand showed an absence of subclinical carriage [29]. By contrast, a study of 251 dogs visiting parks in three cities in south-western Ontario, Canada reported Salmonella in $1.2 \%$ of the dogs [30]. Other studies have reported slightly higher prevalence. Rectal swabs collected from 437 household in northern Taiwan revealed that $2.1 \%$ (9 dogs) were positive for Salmonella spp. [31]. A study of 1391 dogs across Trinidad reported a prevalence of $3.6 \%$ [32] and investigations undertaken in Tehran, Iran and Florida, USA reported even higher prevalences of $4.4 \%$ (21 of 474 dogs) and $15 \%(n=1,626)$ respectively $[33,34]$. This considerable geographical variation in the prevalence of Salmonella serotypes reported in dogs could be due to the sample size, year of sampling, sampling strategies, and isolation methods performed, but may also be due to cultural differences in feeding or hygiene practices or favorable climate conditions for bacterial growth and survival.

The prevalence of Salmonella in dogs as reported in the literature is also highly variable depending on the immediate environment in which the animals live. For example, Salmonella isolation rates from stray dogs have been reported to be significantly higher than those from household dogs [31]. For this reason, in the current study faecal samples were collected and analysed for the presence of salmonellae from dogs housed in a variety of environments: households, rescue centres, boarding kennels, retired greyhound kennels and a pet nutrition facility. It is noteworthy that in this study all kennelled dogs tested negative for the presence of Salmonella, although other studies have reported a higher prevalence of Salmonella shedding in kennelled dogs. Rectal swabs from kennel dogs in Tehran, Iran indicated that 28 out of 181 (15.5\%) were positive for Salmonella [33]. In a shelter in Bursa, Turkey $11 \%$ of dogs tested positive for Salmonella [35], and in Japan, $5.9 \%$ of stray or unwanted apparently healthy dogs were positive for the presence of salmonellae in their intestinal contents [36]. In northern Taiwan rectal swabs collected from 491 stray dogs in a municipal animal shelter found $6.3 \%$ (31 dogs) dogs were positive for salmonellae [31]. However, other studies involving strays or kennelled dogs show much lower rates of carriage that are more in line with the findings presented here. Ojo [37] failed to detect salmonellae in the intestinal contents of stray dogs $(n=100)$ in Trinidad, West Indies, and an analysis of rectal swabs collected from kennelled dogs in Istanbul, Turkey found only one out of 100 (1\%) to be positive for Salmonella [38].

Shedding of Salmonella in faeces is also known to be common among the racing greyhound population. Racing greyhounds in the USA have been shown to have high rates of subclinical shedding of Salmonella at 44 \% [39], and a more recent study reported Salmonella in faeces from $11 \%$ of asymptomatic greyhounds [40]. The high prevalences of Salmonella that are typically reported in greyhounds may be traceable to the high-protein raw meat diet provided for racing. A high prevalence of Salmonella in these raw meat diets has been reported, and identical enterotypes have been found in the faeces of dogs consuming the food, confirming that the diet is the likely source of Salmonella [41]. In some instances, the dogs may not be colonised by Salmonella and may just be passive carriers in which food-borne Salmonella is transiently passing through the intestines. However, studies have shown that raw meat diets contaminated with Salmonella can lead to abortions and high levels of morbidity and mortality in greyhounds through Salmonella infection [42, 43]. In contrast to other studies, none of the retired greyhounds in this study tested positive for Salmonella and this may be due to the fact that they were all fed commercial diets.

In recent years there has been a trend towards the feeding of commercially manufactured pet food in many countries including the UK [9]. This is consistent with the results of the accompanying questionnaire from this study, from which it was clear that the vast majority of dogs (93\% of all dogs sampled) were fed a commercial diet. This may be one of the reasons the overall prevalence of Salmonella in faeces from dogs in the five housing environments studied was relatively low. Although there have been reported instances of Salmonella outbreaks in dogs and humans that were shown to originate from commercial food sources [44], commercial pet foods are typically manufactured in such a way as to minimise the risk of contamination from Salmonella [45].

In the context of racing greyhounds, dogs fed raw meat diets may be at an increased risk of Salmonella exposure, a possibility supported by previous research. For example, in one study Salmonella was isolated from $80 \%$ of the raw meat diet samples and from $30 \%$ of the stool samples from dogs fed the diet [46]. Other studies have also demonstrated high levels of Salmonella in faeces from animals fed raw meat and offal diets [47]. Unfortunately, due to the overwhelming popularity of commercial dog foods used to feed dogs in the current study it is not possible to address this issue directly. This study showed that only two dogs $(0.4 \%)$ were fed a raw meat diet and neither of these dogs was positive for Salmonella shedding. 
The cross-sectional nature of this investigation meant that only a single faecal sample was analysed from each dog, which may be the reason that the prevalence of Salmonella was low. However, although the prevalence of Salmonella might have been higher if more than one faecal culture was performed on each dog this study suggests that the exposure risk is low; however, Salmonella was still identified. The limitations of single faecal cultures for the isolation of Salmonella, due to intermittent shedding, are well documented. Dogs with experimentally-induced latent infection shed the agent irregularly for the subsequent 3-4 weeks. In rare cases this shedding continues for up to 100 days $[48,49]$. Since the agent is being shed at intervals, sampling times are very important when searching the carrier status of the dogs and in the present study we can only conclude that the dogs were positive or negative for the presence of Salmonella at the time of sampling. As an illustration of the intermittent shedding, the Salmonella positive dog in this study was repeat-sampled over three consecutive days but all subsequent samples were negative for the presence of Salmonella.

Further to the point of variability, the Salmonella isolated from the household dog that tested positive was Salmonella arizonae, which was only isolated following pre-enrichment of the faecal sample, suggesting the microorganism was present in low numbers. This subspecies is predominately found in reptiles, such as snakes, lizards and terrapins but has also been reported in dogs [50]. In a report by Public Health England it ranked eleventh of the most frequently reported serotypes in 2013 [1]. Salmonella arizonae has also been reported to cause salmonellosis in humans that have consumed contaminated snake meat or ingested medicines with traces of snake [51, 52]. Typically human cases are from vulnerable groups including immunocompromised, elderly or very young children [1]. However it is the serotypes Enteritidis and Typhimurium that are amongst the most frequently isolated serotypes of Salmonella from clinical cases, both human and animal, in the UK [1], and so the presence of Salmonella arizonae in the dog in this study may be considered atypical.

\section{Conclusions}

In conclusion, this study indicates that the prevalence of subclinical shedding of Salmonella in dogs from the Midlands region of the United Kingdom is low. Good hygiene, sanitation procedures, or time of sampling are likely among the reasons for the absence of Salmonella in the faeces of dogs investigated in this study. It could also be that these dogs are representative of the trend in many developed nations toward feeding commercially prepared dog food rather than table scraps or other foods where Salmonella may be more likely to be present. Clearly, further research on this subject is needed to elucidate these possibilities.

Regardless of these findings, the possibility that dogs may harbour Salmonella and other zoonotic pathogens should not be ignored. Public awareness of good hygiene practices, such as frequent hand washing, can help mitigate the risk of Salmonella infections contracted from dogs just as from other sources.

\section{Methods}

\section{Sample population}

Faecal samples were obtained from 436 dogs located in the Midland region of the UK between 2009 and 2012. The dogs were from different housing environments including households $(n=126)$, rescue centres $(n=96)$, boarding kennels $(n=43)$, retired greyhound kennels $(n=39)$ and a pet nutrition facility $(n=132)$. Owners volunteered to participate in the study. There were no exclusion criteria set for this study and therefore all samples collected were used. Faecal samples from each dog were accompanied by a questionnaire to determine age, sex, breed, diet, medication, gastrointestinal problems and scavenging habits.

The study was considered by the WALTHAM Ethical Review Body and Aston University Ethics committee and approval was obtained. Informed owner consent was obtained for all the dogs that participated in this study.

\section{Faecal sample processing}

Prior to sample testing a positive control for the isolation method was prepared from a sample of fresh homogenised faeces previously determined to be negative for the presence of Salmonella by direct and enrichment culturing methods $[47,53,54]$. Salmonella Typhimurium (NCTC 74) was grown in nutrient broth (NB; Oxoid, UK) to a concentration of $10^{7} \mathrm{cfu} / \mathrm{mL}$, determined spectrophotometrically, and $1 \mathrm{~mL}$ used to spike $25 \mathrm{~g}$ fresh faeces to produce a positive control of approximately $10^{5} \mathrm{cfu} / \mathrm{g}$.

Freshly voided faeces were collected by the owner in sterile bags, maintained at ambient temperature, and submitted to the investigator within $24 \mathrm{~h}$. Samples were analysed for the presence of Salmonella using standard and enrichment culture-based method [47, 53, 54]. Samples were manually homogenised inside the collection bag and $2.5 \mathrm{~g}$ aliquots were taken into $22.5 \mathrm{mls}$ Buffered Peptone Water (BPW; Oxoid, UK) which was mixed thoroughly by agitation. Serial ten-fold dilutions were prepared from the neat faecal suspension in $\mathrm{NB}$ and $0.1 \mathrm{mLs}$ of the $10^{-2}, 10^{-4}$ and $10^{-6}$ dilutions inoculated onto Xylose lysine deoxycholate (XLD) agar, Hektoen enteric agar and Brilliance Salmonella agar (Oxoid, UK). The plates were incubated for $24 \mathrm{~h}$ at $37^{\circ} \mathrm{C}$ to determine the presence of Salmonella. The remainder of the BPW suspension was incubated at $37{ }^{\circ} \mathrm{C}$ for $24 \mathrm{~h}$. Following 
incubation a $0.1 \mathrm{~mL}$ sample was directly added to 9.9 $\mathrm{mL}$ of Rappaport-Vassiliadis enrichment broth (RV; Oxoid, UK) and incubated for $24 \mathrm{~h}$ at $42{ }^{\circ} \mathrm{C}$. A $10 \mu \mathrm{L}$ loop full of the incubated suspension was inoculated on the three selective agars listed above. Following incubation, plates were observed for typical Salmonella morphology and the identity of individual colonies confirmed using Analytical Profiling Index 20E (API; BioMérieux, France), Salmonella agglutination and Wellcolex ${ }^{\bullet}$ Colour Salmonella Rapid Latex agglutination test (Oxoid, UK) according to the manufacturer's instructions. Salmonella colonies were subsequently stored on beads (Microbank $^{\text {rat }}$, Pro-Lab Diagnostics, Canada) at $-80{ }^{\circ} \mathrm{C}$.

\section{Statistical analysis}

The overall prevalence, and its $95 \%$ confidence interval, was estimated using an exact one-sample binomial test [55] using GenStat v 17.1 statistical software (VSN International Ltd).

A sample size calculation found that 100 independent samples would be needed in each population type to detect a difference of $10 \%$ from a baseline of $1 \%$ prevalence (the previously assumed baseline according to published literature) between population types, assuming a two sample binomial test using a $5 \%$ significance level with at least $80 \%$ power. In addition, it was found that with 100 samples a prevalence of $1 \%$ could be estimated to within $2 \%$ (i.e. a $95 \%$ confidence interval 0,3 ) which is deemed fit for purpose.

\section{Competing interests}

This work was funded by the WALTHAM Centre for Pet Nutrition, the employer of Corrin Wallis and Nancy Gee.

\section{Authors' contributions}

$\mathrm{PL}, \mathrm{CW}$, and $\mathrm{ACH}$ conceived and designed the study. PL collected the data, performed data analysis and drafted the paper. CW, NG and ACH advised and offered expertise on Salmonella, dog and human-animal interaction risk factors. PL, CW, NG and ACH edited and approved the final manuscript.

\section{Acknowledgements}

We acknowledge the support of the Biotechnology \& Biological Sciences Research Council (BBSRC) for a CASE studentship to PL, supported by the WALTHAM Centre for Pet Nutrition. We thank the owners of the dogs for their participation in this study.

\section{Author details}

'Life and Health Sciences, Aston University, Birmingham B4 7ET, UK. ${ }^{2}$ WALTHAM Centre for Pet Nutrition, Waltham-on-the-Wolds, Leicestershire LE14 4RB, UK.

Received: 28 January 2015 Accepted: 10 September 2015 Published online: 17 September 2015

\section{References}

1. Public Health England: Gastrointestinal infections data. Summary of Salmonella surveillance, May 2013 [https://www.gov.uk/government/ publications/salmonella-surveillance-summary-2013]

2. European Food Safety Authority. Scientific Opinion of the Panel on Biological Hazards on a request from the European Commission on a quantitative microbiological risk assessment on Salmonella in meat: Source attribution for human salmonellosis from meat. EFSA J. 2008;625:1-32.
3. Majowicz SE, Musto J, Scallan E, Angulo FJ, Kirk M, O'Brien SJ, et al. The global burden of nontyphoidal Salmonella gastroenteritis. Clin Infect Dis. 2010;50:882-9.

4. Vargas-Galindo Á: Probabilistic inversion in priority setting of food borne pathogens. MSc thesis, Delft University of Technology, Department of Applied Mathematics and Risk Analysis 2007. http://www.ewi.tudelft.nl/ fileadmin/Faculteit/EWl/Over_de_faculteit/Afdelingen/ Applied_Mathematics/Risico_en_Beslissings_Analyse/Theses/ Vargas_thesis.pdf

5. Mead PS, Slutsker L, Dietz V, McCaig LF, Bresee JS, Shapiro C, et al. Foodrelated illness and death in the United States. Emerg Infect Dis. 1999:5:607-25.

6. Stehr-Green JK, Schantz PM. The impact of zoonotic diseases transmitted by pets on human health and the economy. Vet Clin North Am Small Anim Pract. 1987:17:1-15.

7. Grant S, Olsen CW. Preventing zoonotic diseases in immunocompromised persons: The role of physicians and veterinarians. Emerg Infect Dis. 1999;5:159-63.

8. Koehler KM, Lasky T, Fein SB, DeLong SM, Hawkins MA, Rabatsky-Her TMS, et al. Population-based incidence of infection with selected bacterial enteric pathogens in children younger than five years of age, 1996-1998. Pediatr Infect Dis J. 2006;25:129-34.

9. Pet Food Manufacturers Association 2014 [http://www.pfma.org.uk/petpopulation-2014] and [http://www.pfma.org.uk/market-history]

10. Esposito L, McCune S, Griffin JA, Maholmes V. Directions in human-animal interaction research: Child development, health, and therapeutic interventions. Child Development Perspectives. 2011;5:205-11.

11. Herzog $\mathrm{H}$. The impact of pets on human health and psychological well-being. Curr Dir Psychol Sci. 2011;20:236-39.

12. McCardle P, McCune S, Griffin JA, Maholmes V. How animals affect us: Examining the influence of human-animal interaction on child development and human health. Washington, D.C, US: American Psychological Association; 2011.

13. Serpell J. Beneficial effects of pet ownership on some aspects of human health and behaviour. J R Soc Med. 1991;84:717-20.

14. Headey B, Grabka MM. Pets and human health in Germany and Australia: National longitudinal results. Soc Res Indicat. 2007;2:297-311.

15. Garrity TF, Stallones L, Marx MB, Johnson TP. Pet ownership and attachment as supportive factors in the health of the elderly. Anthrozoos: A Multidisciplinary Journal of The Interactions of People \& Animals. 1989:38:35-44.

16. Cutt H, Giles-Corti B, Knuiman M, Timperio A, Bull F. Understanding dog owners' increased levels of physical activity: Results from reside. Am J Public Health. 2008;98:66-9.

17. Jackson T. Is it time to ban dogs as household pets? Br Med J. 2005;331:1278.

18. Morse EV, Duncan MA, Estep DA, Riggs WA, Blackburn BO. Canine salmonellosis: a review and report of dog to child transmission of Salmonella enteritidis. Am J Public Health. 1976;66:82-3.

19. Sato Y, Mori T, Koyama T, Nagase H. Salmonella virchow infection in an infant transmitted by household dogs. J Vet Med Sci. 2000:62:767-9.

20. Franklin A. "Beware of the dog": A Post-humanist approach to housing. Theory Soc. 2006;23:137-56.

21. Katz J. The new work of dogs: tending to life, love, and family. New York: Villard: 2003.

22. Burnie AG, Simpson JW, Linsay D, Miles RS. The excretion of Campylobacter, salmonellae and Giardia lamblia in the faeces of stray dogs. Vet Res Comm. 1983;6:133.

23. Carter ME, Quinn JP. Salmonella infections in dogs and cats. In: Wray C, Wray A, editors. Salmonella in domestic animals. Wallingford, UK: CAB International; 2000. p. 231-44

24. Sanchez S, Lee MD, Maurer JJ, Doyle MP. Animal sources of salmonellosis in humans. Vet Med Today. 2002;221:492-7.

25. Stavisky J, Radford AD, Gaskell R, Dawson S, German A, Parsons B, et al. A case-control study of pathogen and lifestyle risk factors for diarrhoea in dogs. Prev Vet Med. 2011;99:185-92.

26. Leonard F. Salmonella infection and carriage: the importance of dogs and their owners. Vet Rec. 2014;174:92-3.

27. Philbey AW, Mather HA, Gibbons JF, Thompson H, Taylor DJ, Coia JE. Serovars, bacteriophage types and antimicrobial sensitivities associated with salmonellosis in dogs in the UK (1954-2012). Vet Rec. 2014;174:94. 
28. The Kennel Club [http://www.thekennelclub.org.uk]

29. Timbs DV, Davis GB, Carter ME, Carman MG. The Salmonella excretor incidence of dogs in Hawke's Bay. N Z Vet J. 1975;23:54-6.

30. Procter TD, Pearl DL, Finley RL, Leonard EK, Janecko N, Reid-Smith RJ, et al. A cross-sectional study examining campylobacter and other zoonotic enteric pathogens in dogs that frequent dog parks in three cities in south-western Ontario and risk factors for shedding of Campylobacter spp. Zoonoses Public Health. 2014:61:208-18.

31. Tsai H-J, Huang H-C, Lin C-M, Lien Y-Y, Chou C-H. Salmonellae and Campylobacters in household and stray dogs in Northern Taiwan. Vet Res Commun. 2007:31:931-9.

32. Seepersadsingh N, Adesiyun AA, Seebaransingh R. Prevalence and antimicrobial resistance of Salmonella spp. in non-diarrhoeic dogs in Trinidad. J Vet Med B Infect Dis Vet Public Health. 2004;51:337-42.

33. Shimi A, Keyhani M, Bolurchi M. Salmonellosis in apparently healthy dogs. Vet Rec. 1976;98:110-1.

34. Galton MM, Scatterday JE, Hardy AV. Salmonellosis in dogs. I. Bacteriological, epidemiological and clinical considerations. J Infect Dis. 1952;91:1-5.

35. Kocabiyik AL, Cetin C, Dedicova D. Detection of Salmonella spp. in Stray Dogs in Bursa Province, Turkey: First Isolation of Salmonella corvallis from Dogs. J Vet Med B. 2006:53:194-6.

36. Fukushima H, Nakamura R, litsuka S, Ito Y, Saito K. Presence of zoonotic pathogens (Yersinia spp., Campylobacter jejuni, Salmonella spp., and Leptospira spp.) simultaneously in dogs and cats. Zentralbl Bakteriol Mikrobiol Hyg B. 1985;181:430-40.

37. Ojo MO. Pathogenic aerobic bacteria and fungi isolated from stray dogs in Trinidad. Rev Elev Med Vet Pays Trop. 1994;47:179-81.

38. Baggigil AF, Ikiz S, Dokuzeylul B, Basaran B, Or E, Ozgur Y. Fecal shedding of Salmonella spp. In dogs Bacteriology. J Vet Med Sci. 2007;9:775-7.

39. Stucker CL, Galton MM, Cowdery J, Hardy AV. Salmonellosis in dogs. II. Prevalence and distribution in greyhounds in Florida. J Infect Dis. 1952;91:6-11.

40. Stone GG, Chengappa MM, Oberst RD, Gabbert NH, McVey S, Hennessy KJ, et al. Application of polymerase chain reaction for the correlation of Salmonella serovars recovered from greyhound feces with their diet. J Vet Diagn Invest. 1993;5:378-85.

41. Chengappa MM, Staats J, Oberst RD, Gabbert NH, McVey S. Prevalence of Salmonella in raw meat used in diets of racing greyhounds. J Vet Diagn Invest. 1993;5:372-7.

42. Caldow GL, Graham MM. Abortion in foxhounds and ewe flock associated with Salmonella montevideo infection. Vet Record. 1998;142:138-9.

43. Morley PS, Strohmeyer RA, Tankson JD, Hyatt DR, Dargatz DA, Fedorka-Cray PJ. Evaluation of the association between feeding raw meat and Salmonella enterica infections at a Greyhound breeding facility. J Am Vet Med Assoc. 2006;228:1524-32.

44. CDC. Update: recall of dry dog and cat food products associated with human Salmonella schwarzengrund infections-United States. MMWR Morb Mortal Wkly Rep. 2008;57:1200-2.

45. FDA, Good Manufacturing Practices: http://www.gmpguide.com/foodgmp.htm

46. Joffe DJ, Schlesinger DP. Preliminary assessment of the risk of Salmonella infection in dogs fed raw chicken diets. Can Vet J. 2002;43:441-2.

47. Finley R, Ribble C, Aramini J, Vandermeer M, Popa M, Litman M, et al. The risk of salmonellae shedding by dogs fed Salmonella-contaminated commercial raw food diets. Can Vet J. 2007:48:69-75.

48. Weber A, Wachowitz R, Weigl U, Schäfer-Schmidt R. Occurrence of Salmonella in fecal samples of dogs and cats in northern Bavaria from 1975 to 1994. Berliner und Münchener tierärztliche Wochenschrift. 1995;108:401-4.

49. Tanaka $Y$, Katsube $Y$, Imaizumi K. Experimental carrier in dogs produced by oral administration of Salmonella typhimurium. Nippon Juigaku Zasshi. 1976;38:569-78.

50. Edwards PR, Fife MA, Ramsey CH. Studies on the Arizona group of Enterobacteriaceae. Bacteriol Rev. 1959;23:155-74.

51. Di Bella S, Capone A, Bordi E, Johnson E, Musso M, Topino S, et al. Salmonella enterica ssp. arizonae infection in a 43-year-old Italian man with hypoglobulinemia: a case report and review of the literature. J Med Case Rep. 2011;5:323.

52. Hoag JB, Sessler CN. A comprehensive review of disseminated Salmonella arizona infection with an illustrative case presentation. South Med J. 2005:98:1123-9.
53. Public Health England. UK Standards for Microbiology Investigations. Identification of Salmonella species. March 2014. [https://www.gov.uk/ government/uploads/system/uploads/attachment_data/file/344052/ ID 24i2.3.pdf]

54. Mainar-Jaime RC, Andres S, Vico JP, San Roman B, Garrido V, Grillo MJ. Sensitivity of the ISO 6579:2002/Amd 1:2007 standard method for detection of Salmonella spp. on mesenteric lymph nodes from slaughter pigs. J Clin Microbiol. 2013;51:89-94.

55. Armitage P, Berry G, Matthews JNS. Analysing means and proportions. In: Statistical methods in medical research. 4th ed. Oxford: Blackwell Science; 2002. p. 83-146.

\section{Submit your next manuscript to BioMed Central and take full advantage of:}

- Convenient online submission

- Thorough peer review

- No space constraints or color figure charges

- Immediate publication on acceptance

- Inclusion in PubMed, CAS, Scopus and Google Scholar

- Research which is freely available for redistribution 